University of Louisville

ThinkIR: The University of Louisville's Institutional Repository

Faculty Scholarship

9-12-2019

\title{
Happiness and healthiness: A replication study
}

\author{
Kobena Osam \\ Northern Kentucky University \\ Brad Shuck \\ University of Louisville, brad.shuck@louisville.edu \\ Jason Immekus \\ University of Louisville
}

Follow this and additional works at: https://ir.library.louisville.edu/faculty

Part of the Educational Assessment, Evaluation, and Research Commons, and the Educational

Leadership Commons

Original Publication Information

Osam, Kobena, Brad Shuck and Jason Immekus. "Happiness and Health: A Replication Study." 2019.

Human Resource Development Quarterly Advance online publication, doi.org/10.1002/hrdq.21373

\section{ThinkIR Citation}

Osam, Kobena; Shuck, Brad; and Immekus, Jason, "Happiness and healthiness: A replication study" (2019). Faculty Scholarship. 439.

https://ir.library.louisville.edu/faculty/439

This Article is brought to you for free and open access by ThinkIR: The University of Louisville's Institutional Repository. It has been accepted for inclusion in Faculty Scholarship by an authorized administrator of ThinkIR: The University of Louisville's Institutional Repository. For more information, please contact thinkir@louisville.edu. 


\section{Happiness and healthiness: A replication study}

\section{Kobena Osam ${ }^{1}$ ๑ | Brad Shuck ${ }^{2}$ @ | Jason Immekus ${ }^{2}$}

${ }^{1}$ College of Arts and Sciences, Northern Kentucky University, Highland Heights, Kentucky

${ }^{2}$ College of Education and Human Development, University of Louisville, Louisville, Kentucky

\section{Correspondence}

Kobena Osam, College of Arts and Sciences, Northern Kentucky University, Nunn Drive, Highland Heights, KY 41099.

Email: osame1@nku.edu

\begin{abstract}
Research coalescing around psychological climate, engagement, and well-being has been receiving considerable attention in management and human resource development (HRD) literature. However, research associated with these variables has generally been limited to for-profit businesses and organizations with little attention within the context of institutions of higher education. In response, this crosssectional replication study examined the extent to which psychological climate, engagement, and well-being were associated with each other in higher educational institutions. Study data included a sample of 259 individuals employed by institutions of higher education in the United States. Using mediation analyses, the study found that psychological climate, engagement, and well-being were positively associated with each other, and that engagement mediated the relationship between psychological climate and well-being. Implications for HRD theory and research, as well as specific recommendations for leaders and administrators in higher education are discussed.
\end{abstract}

\section{KEYWORDS}

employee engagement, psychological climate, well-being

\section{1 | INTRODUCTION}

Since the turn of the century, scholars and practitioners in human resource development (HRD) and management have sought to create and sustain positive organizational change (Kim, Kolb, \& Kim, 2013). This interest has been supported by the idea that focusing on the positive aspects of an organization leads to more positive individual and organizational performance (Watkins \& Stavros, 2010). This line of research is a purposeful departure from the deficit-based approach, which addressed only the negative aspects of the work environment such as burnout and 
exhaustion (Altunel, Kocak, \& Cankir, 2015; Kim et al., 2013). One of the more popular approaches stemming from the interest in positive work environments has been the construct of employee engagement (Kim et al., 2013). Employee engagement is defined as a positive psychological state related to the work environment and research has routinely suggested that increased levels of engagement are related to positive organizational outcomes (Kim et al., 2013; Shuck, Osam, Zigarmi, \& Nimon, 2017; Shuck \& Wollard, 2010) such as job commitment (Christian, Garza, \& Slaughter, 2011; Shuck \& Reio Jr, 2014), increased retention (Hableson, 2010), improved performance (Kim et al., 2013), and better financial returns (Xanthopoulou, Bakker, Demerouti, \& Schaufeli, 2009).

More recently, scholars have broadened the net of engagement research to include an understanding of the potential impact on the individual employee, and more specifically, a connection with health and well-being (Fairlie, 2017). Initial evidence from this still emerging line of research has suggested that employee engagement is associated with more positive levels of well-being. For example, higher levels of engagement are associated with fewer physical body complaints such as headaches and stomachaches (Schaufeli, Taris, \& Van Rhenen, 2008), better quality of sleep (Shuck, Alagaraja et al., 2017), and better psychological well-being (Shuck \& Reio, 2014). At present, however, such research is limited, prompting calls from HRD scholars for further work in this area (cf. Fairlie, 2017)-and especially a focus on the role of health and well-being in maintaining positive levels of organizational performance (Goetzel et al., 2014). The field of research on employee engagement has grown to include an examination of the engagement construct within specific professional contexts, such as health care (Keyko, Cummings, Yonge, \& Wong, 2016; Pfaff, Baxter, Jack, \& Ploeg, 2014) and retail (James, McKechnie, \& Swanberg, 2011). This research has been used to better understand how engagement functions by industry and what nuances exist between specific industry occupations (García-Sierra, Fernández-Castro, \& Martínez-Zaragoza, 2016). While research is available on a wide variety of industry-specific outcomes related to employee engagement, there is a dearth of research on engagement in higher education (Nazir \& Islam, 2017). Indeed, there is almost no research on the impact, influence, or association of employee engagement in higher education at this time. The purpose of our work was to explore the relevance of employee engagement in a higher education setting using contextual factors previously identified in the literature. Specifically, heeding calls for replication research in HRD (Reio Jr, 2016), this work is a replication study of prior research by Shuck and Reio (2014). In what follows, we lay out a case for the re-examination of the variables in Shuck and Reio's study, provide a theoretical framework for our present-day work, detail the methods and results and finally, and discuss implications of our findings for HRD.

\section{2 | CONTEXTUAL BACKGROUND}

The changing context of higher education has recently piqued the interest of human resource and management scholars and practitioners alike (Shin \& Jung, 2014; Silman, 2014). Dwindling financial resources and tighter budget measures are affecting many colleges and universities, resulting in a change in performance management. This change is designed to result in more efficient and cost-effective operations, yet to be clear, the available research is murky at best (Parker, 2011; Shin \& Jung, 2014). This line of research includes a performance-based management approach that has modified expectations of academic employees. For example, often Unit-level Deans are being evaluated by their ability to attract external funding while establishing new models of leadership in an increasingly corporate environment (Giroux, 2009). Moreover, faculty are expected to teach and advise larger, more diverse numbers of students (Osam, Bergman, \& Cumberland, 2017), while simultaneously obtaining external research funding and publishing in high quality, high impact outlets (Kinman, 2014). The net result of these changes suggests that higher education is changing in ways that is potentially producing a more stressful work environments (Shah, 2012). This stress level is leading to concerns about the relevance and influence on employee engagement in a higher education context as well as the impact of engagement on the overall health and well-being of university employees (Silman, 2014; Van den Berg, Bakker, \& Ten Cate, 2013). 
In general, empirical research on employee engagement has focused on the utility of engagement in predicting traditional indicators of workplace performance such as job attitudes (Rich, Lepine, \& Crawford, 2010) and revenue generation (Harter, Schmidt, Asplund, Killham, \& Agrawal, 2010). These studies all come to a similar conclusion: there is a reliably positive association between employee engagement and workplace performance (Shuck \& Reio, 2014). Interestingly, most studies on engagement ground their framework in a deficit-based approach (c.f., Altunel et al., 2015; Kim et al., 2013). This is often depicted as a negative relationship between engagement and variables considered to be factors of "un-wellbeing" that adversely impact productivity and performance (Shuck \& Reio, 2014) such as burnout (Schaufeli \& Bakker, 2010) and workaholism (Demerouti, Mostert, \& Bakker, 2010). Certainly these frameworks have utility in light of the movement toward positive organizational change in HRD (Kim et al., 2013). Furthermore, there have been calls to identify workplace components that lead to higher engagement, while also improving employees' overall well-being (Schaufeli, 2012). A more positive framework takes into account that engagement is not a continuum state-rather, engagement and disengagement may be separate motivational states, and thus theoretical frameworks grounded in deficit-based approaches may miss important and potentially impactful nuances of the engagement $\rightarrow$ well-being relationship.

Based on these ideas, Shuck and Reio (2014) conducted a study exploring the relationship between psychological workplace climate, employee engagement, and well-being using a sample of health care professionals. Their research was grounded in seminal work on psychological climate by Brown and Leigh (1996), which focused on the perception of the workplace environment and how perceptions affected employee well-being. Ultimately, Shuck and Reio's work sought to identify how employees' experience of their psychological workplace climate affected their interpretation of their work as engaging or otherwise, and whether engagement would influence the relationship between psychological climate and well-being. Their findings suggested two key outcomes: (a) that psychological climate did indeed affect employees' engagement and (b) engagement significantly influenced the strength and direction of the relationship between psychological workplace climate and well-being. The primary purpose of the present study was to examine the generalizability of their findings within the context of higher education. Additionally, we also sought to extend Shuck and Reio's research by examining the impact of psychological workplace climate and engagement on physical well-being - a previously untested relationship in the HRD literature.

\section{3 | THEORETICAL FRAMEWORK}

This study adopts the framework developed by Shuck and Reio (2014) that specifies that the relationship between workplace climate, employee engagement, and well-being could be best interpreted from Fredrickson's (1998) Broaden-and-Build Theory of Positive Emotions.

\subsection{Broaden and build theory: A brief overview}

Fredrickson (2001) suggested that positive emotions could lead to an increase in cognitive and emotional resources, thus allowing individual improvement in outcomes such as creativity and critical thinking. In contrast, experiencing negative emotions constricted resources and closed off available outlets of resource and energy. According to Fredrickson, such outcomes are fleeting and heavily dependent on a steady supply of positive emotion, a state that cannot be realistically sustained indefinitely-similar to contemporary conceptualizations of employee engagement. Notwithstanding, fleeting moments of positive emotions enable a person to "pursue a wider range of thoughts and actions than is typical" (Fredrickson \& Branigan, 2005, p. 314). For example, employees who have positive experiences of the workplace have also reported increases in scope of attention and execution of action plans (Fredrickson \& Branigan, 2005). This indicates that experiencing positive emotions has positive implications for task related behaviors in the workplace and signals a likely connection to engagement theory and research (Shuck \& Reio, 
2014; Shuck \& Wollard, 2010). It also highlights the importance of psychological climate, as the meaning an individual ascribes to the workplace determines the intensity and direction of their energy toward organizational outcomes.

\subsection{Engagement and psychological climate in the context of broaden and build}

Engagement and psychological climate are interconnected and interpretable using the basic premise of broaden and build theory. Psychological climate theory, for example, is focused on the interpretation of psychological perceptions of the workplace (Brown \& Leigh, 1996). Psychological climate is defined as the degree to which employees deem their organizations to be meaningful and safe places to work (Brown \& Leigh, 1996). Brown and Leigh further explained that psychological climate was the lens through which employees assessed their work environment in relation to how it might affect their well-being. Later research revealed that psychological climate was associated with engagement, and that both variables were strong predictors of turnover intention and effort (Shuck \& Reio, 2014; Shuck, Reio, \& Rocco, 2011). That is, positive interpretations of the psychological workplace climate lead to the experience of positive emotions that triggered higher levels of engagement and subsequently lead to desirable organizational outcomes linked to engagement such as better customer satisfaction, improved performance, lower turnover etc. (Shuck \& Reio, 2014).

\section{3 | Well-being and broaden and build}

Well-being was originally grounded in a deficit approach to management and was measured by factors of "unwellness" such as burnout, emotional exhaustion, and depersonalization (Maslach, Schaufeli, \& Leiter, 2001; Schaufeli et al., 2008). Past research indicated that individuals who showed signs of being unwell also reported negative psychological climates at work (Shuck \& Reio, 2014). In their study of psychological climate and well-being, Iverson, Olekalns, and Erwin (1998) found that employees who had negative psychological workplace experience also reported higher levels of emotional exhaustion and depersonalization, restricting their ability to realize positive outcomes (i.e., feelings of accomplishment). In more recent research, Shuck et al. (2011) suggested that specific negative workplace experiences (e.g., lack of peer/managerial support) make it less likely for experiences of positive emotion and subsequently adversely impact well-being. Similarly, in their study of health care professionals Eisele and D'Amato (2011) found that psychological climate and "un-wellness" (i.e., emotional exhaustion and burnout) were negatively associated. Within the context of the Broaden and Build Theory, findings from these studies suggested that negative workplace climates limit the ability of employees to broaden available emotional resources toward workplace tasks and increase the potential negative effects on well-being (Shuck \& Reio, 2014).

While information on the relationship between psychological climate-well-being research is not lacking, it has generally been limited to deficit-based approaches only. As scholarly interest has shifted toward a more positive approach to management (Kim et al., 2013), Shuck and Reio's study examined well-being from the eudiamonia approach. Eudiamonia revolves around life satisfaction as a key indicator of psychological well-being (Ryff \& Keyes, 1995), and concerns itself with the extent to which individuals feel fulfilled, and are able to realize their full potential (Grant et al., 2007). Because this study replicated Shuck and Reio's work, it also examined well-being from a eudiamonia perspective using psychological well-being as an outcome factor. However, we extendend Shuck and Reio's work by examining physical well-being in addition and defined it as the presence or absence of sickness. Therefore, in this study, two forms of well-being are explored; psychological well-being and physical well-being.

\section{4 | Hypotheses development}

Past research suggested that workplace environment determines whether employees will have positive or negative interpretations of the psychological climate (Brown \& Leigh, 1996), and that this interpretation influences an employee's decision to fully immerse themselves in their work and be engaged (Shuck et al., 2011; Shuck \& Reio, 
2014). Additionally, research has suggested that negative experiences of psychological climate are linked with poorer well-being outcomes (Eisele \& D'Amato, 2011; Shuck et al., 2011) Furthermore, recent research has suggested that higher levels of engagement are also associated with higher levels of well-being (see Fairlie, 2017; Shuck et al., 2017). For this study, based on historical work, we expected psychological climate, engagement, and well-being to share a positive association.

Hypothesis 1: There is a positive relationship between psychological climate, engagement, and well-being.

Utilizing the Broaden and Build Theory, we examined the extent to which positive interpretations of psychological workplace climate are associated with increased cognitive and emotional resources that may lead to higher levels of engagement, and, consequently, more employer-desired outcomes (e.g., lower turnover). Because of the emergent link between engagement and well-being (c.f., Fairlie, 2017), it is possible that a linear relationship exists where psychological climate influences the level of engagement, and that the level of engagement in turn impacts employee well-being. This further suggested that an indirect relationship might be possible between psychological climate and well-being, and that this relationship could be mediated by employee engagement. Additionally, past research has suggested that the impact of psychological climate on individual and organizational outcomes is indirect, and can be determined through measuring the mediating effect of variables such as engagement (Brown \& Leigh, 1996; Eisele \& D'Amato, 2011; Kataria, Rastogi, \& Garg, 2013). Here, we expected two outcomes based on our two interpretation of well-being-psychological and physical. First, we expected engagement to mediate the relationship between psychological climate and psychological well-being, and second, between psychological climate and physical well-being.

Hypothesis 2a: Engagement will mediate the relationship between psychological climate and psychological well-being.

Hypothesis 2b: Engagement will mediate the relationship between psychological climate and physical well-being.

In the next section, we detail the methods of our work including the research methods and study measures directly linked to our hypotheses.

\section{4 | METHOD}

This study used a cross-sectional survey research design for data collection. The survey was administered online via email using public listserves consisting of faculty and staff at institutions of higher education across the United States. To participate in this study, individuals had to be employed by an institution of higher education as faculty or staff in the United States. A total of 259 participants were obtained for the study using a convenience sample. Participants received invitation to survey via email that contained information on informed consent and a link to the survey. Clicking on the survey link was considered as acknowledgement of informed consent.

The final sample size was 259. This included 182 individuals (70\% females), $82 \%$ from 4-year public institutions $(n=212), 12 \%$ from 4 year private institutions $(n=32)$, and $6 \%$ from 2 year public institutions $(n=15)$. More than $50 \%$ reported current length of employment as between 0 and 5 years $(n=132)$. The percentage of the final sample employed as faculty was $43 \%(n=111)$ while staff was $57 \%(n=148)$. Racial diversity was represented by $3 \%$ Asian, 14\% Black or African American, 3\% Hispanic or Latino, $77 \%$ White, and $2 \%$ two or more races.

\section{1 | Research measures}

This study used four measures to operationalize the study variables. Specifically, well-being was defined as the overall quality of an employee's experience and functioning at work, including their physical health and subjective 
workplace experiences (Schaufeli et al., 2008). Two scales were used to operationalize well-being, including a psychological well-being scale and a physical well-being scale, consistent with previous research on well-being (cf. Schaufeli et al., 2008). We describe the study variables later, starting with psychological climate, followed by engagement and, lastly, well-being.

\subsection{1 | Psychological climate}

The Psychological Climate Measure (PCM; Brown \& Leigh, 1996) was used to assess workplace climate. The PCM has 21 items and responses to items on the PCM are based on a 5-point Likert Scale (1 = Strongly disagree, 2 = Disagree, 3 = Neither agree nor disagree, 4 = Agree, and 5 = Strongly agree). Cronbach's coefficient alpha for the study sample was 90 (95\% Cls: 0.88-0.92). A sample item from the PCM is "I rarely feel my work is taken for granted."

\subsection{2 | Employee engagement}

The Employee Engagement Scale (EES) developed by Shuck et al. (2017) was used to measure engagement. The EES is a 12 -item measure scored on a 5 point Likert scale $(1=$ Strongly disagree, $2=$ Disagree, $3=$ Neither agree nor disagree, 4 = Agree, and 5 = Strongly agree). For this study, Cronbach's coefficient alpha was .88 (95\% Cls: 0.86-0.90). A sample item from the EES is "I feel a strong sense of belonging to my job."

\subsection{3 | Psychological well-being}

The Ryff Psychological Well-Being (RPWB) Scale (Ryff, 1995) was used to measure psychological well-being. The RPWB consists of 18 items scored on a 6-point Likert Scale (1 = Strongly disagree, 2 = Moderately disagree, 3 = Slightly disagree, 4 = Slightly agree, 5 = Moderately agree, and 6 = Strongly agree). For this study, Cronbach's coefficient alpha was .81 (95\% Cls: 0.77-0.84). An example of an item from the RPWB is "The demands of everyday life often get me down."

\subsection{4 | Physical well-being}

Physical well-being was measured using the Medical Outcomes Study-Short Form (MOS-20; Stewart, Hays, \& Ware, 1988). The four-item health perception subscale is scored on a 5-point Likert Scale (1 = Definitely true, $2=$ Mostly true, 3 = Not sure, 4 = Mostly false, and 5 = Definitely false). The MOS-20 has been used in previous research on engagement and well-being (see Shuck et al., 2017). For this study, Cronbach's coefficient alpha was .84 (95\% Cls: 0.81-0.87). A sample item from the MOS-20 is "I am as healthy as anybody I know."

\section{5 | RESULTS}

Descriptive statistics including means, correlations, SD, and internal consistency reliability for the measures of psychological climate, engagement, psychological well-being, and physical well-being are reported in Table 1. As reported, the internal consistency reliability estimates exceeded .80 and, thus, were deemed acceptable (see Henson, 2001).

\section{1 | Correlation analysis}

For Hypothesis 1, Pearson Product-Moment correlation coefficients were used to quantify the relationship between psychological climate, engagement, and well-being. To determine effect size, Cohen's (1988) criteria were used 
TAB LE 1 Descriptive statistics and correlations for psychological climate, engagement, and well-being

\begin{tabular}{|c|c|c|c|c|c|c|c|}
\hline & \multirow[b]{2}{*}{ Cronbach's alpha } & \multirow[b]{2}{*}{ Mean (SD) } & \multirow[b]{2}{*}{ Range } & \multicolumn{4}{|c|}{ Correlations } \\
\hline & & & & 1 & 2 & 3 & 4 \\
\hline 1. Psychological climate & .90 & $76.8(12.4)$ & 63 & - & & & \\
\hline 2. Engagement & .88 & $49.2(6.5)$ & 38 & $.52 * *$ & - & & \\
\hline 3. Psychological well-being & .81 & $87.7(9.7)$ & 51 & $.30 * *$ & $.33 * *$ & - & \\
\hline 4. Physical well-being & .84 & $15.4(3.6)$ & 16 & $.17 * *$ & $.15^{*}$ & $.34 * *$ & - \\
\hline
\end{tabular}

Note: $N=259$.

$* * p<.01 ; * p<.05$.

TABLE 2 Direct and indirect effects

\begin{tabular}{|c|c|c|c|c|c|}
\hline Estimated parameters & Standardized coefficients & SE & $t$ & $p$ & BC 95\% Cl lower/upper \\
\hline \multicolumn{6}{|l|}{ Direct effects } \\
\hline $\mathrm{PC} \rightarrow$ Eng $(a)$ & .27 & .03 & 9.6 & $.001 * *$ & \\
\hline Eng $\rightarrow \mathrm{PW}(b)$ & .36 & .10 & 3.5 & $.001 * *$ & \\
\hline $\mathrm{PC} \rightarrow \mathrm{PW}(c)$ & .23 & .05 & 4.9 & $.001 * *$ & \\
\hline $\mathrm{PC} \rightarrow \mathrm{PW}\left(c^{1}\right)$ & .13 & .05 & 2.5 & $.01^{*}$ & \\
\hline \multicolumn{6}{|l|}{ Indirect effects } \\
\hline $\mathrm{PC} \rightarrow$ Eng $\rightarrow \mathrm{PW}$ & .09 & & & & $.05 / .15$ \\
\hline
\end{tabular}

Abbreviations: Eng, engagement; PC, psychological climate; and PW, psychological well-being. $* * p<.01 ; * p<.05$.

$(\geq 0.10=$ small; $\geq 0.30=$ moderate and $\geq 0.50=$ strong $)$. Table 2 reports the Pearson Product-Moment correlation coefficient estimates obtained. As shown, employees' perception of their psychological climate was positively correlated with their engagement levels $(r=.52, p<.01)$, their psychological well-being $(r=.30, p<.01)$, and their physical well-being $(r=.17, p<.01)$. Employee engagement was positively correlated with psychological well-being $(r=.33$, $p<.01)$ and physical well-being $(r=.15, p<.05)$. While the correlations were positive and significant, the relationships between psychological climate and physical well-being, engagement and psychological well-being, and engagement and physical well-being were weak. In summary, results indicated significant associations with each other thus providing support for the first hypothesis.

\section{2 | Mediation analysis}

A series of multiple regressions were used to test Hypotheses $2 \mathrm{a}$ and $2 \mathrm{~b}$, outlined in the mediation model depicted later.

The key model parameter was the significance of the indirect effect of psychological climate on well-being through employee engagement. Mediation was tested using PROCESS software and included the bootstrap approach (Hayes \& Rockwood, 2017). In mediation (see Figure 1), a variable $(X)$ affects another variable $(Y$ ) because it affects a mediating variable (M), which in turn transmits the effects of $X$ to $Y$ (Hayes \& Rockwood, 2017). There are different statistical approaches that can be used to examine mediation. The most popular approach used is the test of causal steps that was developed by Baron and Kenny (1986). However, more recently, this approach has waned in popularity due to more contemporary mediation research that eliminates the need for significance testing of the $a$ and $b$ paths (see Figure 1 ) as a requirement to determine mediation (Hayes \& Rockwood, 2017). The mediating 


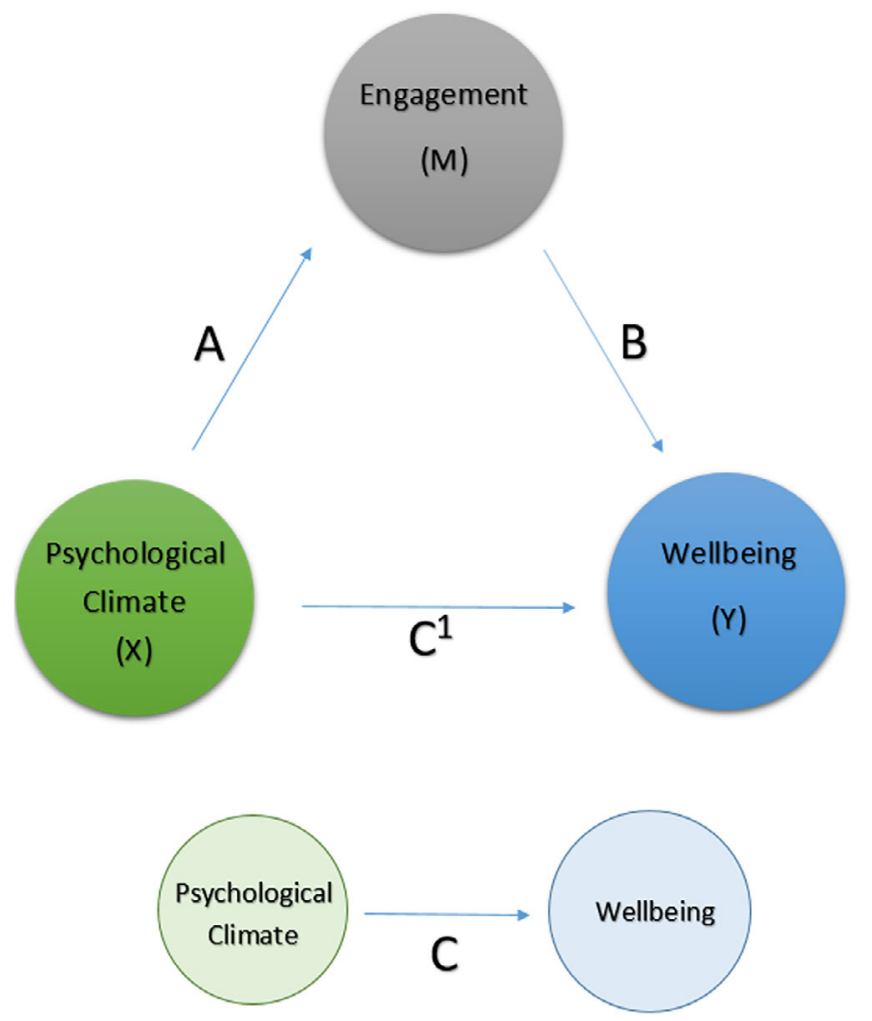

FIGURE 1 Simple mediation model

effect of engagement on psychological climate and psychological well-being was tested by examining the paths exhibited in Figure 1. First, engagement was regressed on psychological climate to establish the coefficient for path a. The regression model was significant $\left(F\left([1,257]=92.88, p<.001\right.\right.$, and $\left.R^{2}=.27\right)$, indicating that psychological climate predicted engagement. This resulted in a significant path (a) from psychological climate to engagement $(\beta=.27$, $t=.96$, and $p<.001$ ) that demonstrated that psychological climate was positively associated with the mediator variable of engagement. Next, psychological well-being was regressed on psychological climate and engagement to establish the coefficient for path $b$. The regression model was significant $\left[F(2,256)=18.97, p<.001\right.$, and $\left.R^{2}=.13\right]$, and suggested that together, psychological climate and engagement explained $13 \%$ of the variance in psychological well-being. As expected, the resulting path $(b)$ from engagement to psychological well-being was statistically significant $(\beta=.36, t=3.5$, and $p<.001)$. Thus, for every unit increase in engagement, there was a corresponding increase of .36 in psychological well-being when all other variables are held constant. In line with contemporary approaches to mediation (see Hayes \& Rockwood, 2017), the indirect effect of psychological climate on psychological well-being (path $a b$ ) was computed to establish mediation. This was done by multiplying coefficients for paths $a$ and $b$ and resulted in a coefficient value of .09 (see Table 2). The coefficient of $a b$ represents a quantification of the difference between the effect of psychological climate on psychological well-being when engagement is controlled versus when it is not (Hayes \& Rockwood, 2017).

A 95\% bias corrected bootstrap confidence interval for the indirect effect was constructed by resampling the data 5,000 times to test the significance of path $a b$. The confidence interval was between 0.05 and 0.15 and, as it did not include 0 , served as evidence that the indirect effect was statistically significant, and, second, that engagement mediated the relationship between psychological climate and well-being.

The aforementioned analysis was also used to test for mediation between psychological climate and physical well-being. Engagement was regressed on psychological climate resulting in a significant path $a(\beta=.27, t=9.6$, and 
TABLE 3 Direct and indirect effects

\begin{tabular}{|c|c|c|c|c|c|}
\hline Estimated parameters & Standardized coefficients & SE & $t$ & $p$ & BC 95\% Cl lower/upper \\
\hline \multicolumn{6}{|l|}{ Direct effects } \\
\hline $\mathrm{PC} \rightarrow \operatorname{Eng}(a)$ & .27 & .03 & 9.6 & $.001 *$ & \\
\hline Eng $\rightarrow \mathrm{PhW}(b)$ & .05 & .04 & 1.2 & .20 & \\
\hline $\mathrm{PC} \rightarrow \mathrm{PhW}(c)$ & .05 & .02 & 2.7 & $.007 *$ & \\
\hline $\mathrm{PC} \rightarrow \mathrm{PhW}\left(c^{1}\right)$ & .03 & .02 & 1.7 & .09 & \\
\hline \multicolumn{6}{|l|}{ Indirect effects } \\
\hline $\mathrm{PC} \rightarrow$ Eng $\rightarrow$ PhW & .01 & & & & $-.001 / .03$ \\
\hline
\end{tabular}

Abbreviations: Eng, engagement; PC, psychological climate; PhW, physical well-being. $* p<.01$.

$p<.001)$ and model $\left[F(1,257)=92.88, p<.001\right.$, and $\left.R^{2}=.27\right]$. The regression coefficient for path $b(\beta=.05, t=1.2$, and $p>.05)$ was not statistically significant, however, the resulting model was significant $[F(2,256)=4.50, p=.01$, and $R^{2}=.03$ ]. The indirect effect or path $a b$ was computed and resulted in a coefficient of .01 . Using the bootstrap procedure, the coefficient of $a b$ was found to be nonsignificant as it yielded confidence intervals that contained 0 (-0.001 to 0.03). Thus, employee engagement did not mediate the relationship between psychological climate and physical well-being and, therefore, Hypothesis $2 \mathrm{~b}$ was not supported (Table 3 ).

\section{6 | DISCUSSION}

Our analysis from Hypothesis 1 provided evidence that positive relationships existed between psychological climate, engagement, and well-being within the context of higher education. The magnitude of the correlation coefficients suggested that these relationships were generally small to moderate (Hemphill, 2003). These results mirrored findings from previous research that found moderate correlations between psychological climate and engagement (Kataria, Garg, \& Rastogi, 2013; Kataria et al., 2013; Shuck \& Reio, 2014). Furthermore, it added additional evidence to previous research that an employees' perception of psychological climate was indeed connected to their wellbeing (Brown \& Leigh, 1996; Shuck \& Reio, 2014). Overall, the results from this study provided support for the continued use of Broaden and Build Theory (Fredrickson, 1998) within the context of workplace environment, as well as extends its use specifically within higher education-a context that had not been previously examined. Continued research is recommended to more fully examine the nature of this relationship, particularly across different higher education institution types.

According to our findings, when employees perceive their workplaces as positive they draw on existing cognitive and emotional resources that enable them to be more engaged, resulting in improved levels of psychological wellbeing. Conversely, this study showed working in negative workplace climates inhibits the ability to expand cognitive and emotional resources leading to lower levels of engagement and resulting in poorer outcomes on psychological well-being. These results stand in parallel to previous research demonstrating the connection between workplace climate and individual and organizational level outcomes such as well-being and engagement (Shuck et al., 2011; Shuck \& Reio, 2014).

For Hypothesis 2a, evidence suggested that employee engagement mediated the relationship between psychological climate and psychological well-being. Our analyses revealed that higher levels of engagement provided a connection between psychological climate and psychological well-being. Employees who reported being engaged were more likely to also have improved levels of well-being that could be linked to their work environment. Supported by previous research, this study showed that the relationship between psychological climate and psychological wellbeing was in essence influenced by engagement (Shuck \& Reio, 2014). This finding also provided support for several 
climate-engagement models grounded in the deficit-based approach to establish the effect of negative work environments on well-being (see Demerouti et al., 2010; Schaufeli et al., 2008; Schaufeli \& Bakker, 2010). Further, our work demonstrated continued support for using a more positive approach to management (see Kim et al., 2013) to examine and elevate characteristics of the work environment that positively impact well-being.

Results from Hypothesis $2 \mathrm{~b}$ indicated that engagement did not mediate the relationship between psychological climate and physical well-being. When juxtaposed with previous literature on engagement and well-being (Fairlie, 2017; Schaufeli et al., 2008; Shuck et al., 2017), this finding was surprising. Generally, higher engagement has often been linked with better reports of physical health when both objective, subjective, and proxy measure of physical well-being have been used (Fairlie, 2017; Schaufeli et al., 2008). We believe that the divergence of our results from findings in the literature can be partly attributed to the MOS-10 (Stewart et al., 1988). The MOS-10 (Stewart et al., 1988) sought participants' subjective opinion of their general health in relation to other people that they know. For example, if a participant knew people who considered themselves to be very ill, they would be likely to rate their health as excellent even if they had health problems of their own. This may have somewhat limited the information on physical well-being (through range restriction) and provides an extended opportunity for HRD scholars to conduct further research in the area of physical well-being.

In sum, our results confirmed Shuck and Reio (2014) study on psychological climate, engagement, and well-being. Specifically, we note that (a) positive associations exist between psychological climate, engagement, and well-being and (b) that there was evidence for an indirect relationship between psychological climate and psychological wellbeing through employee engagement. Evidence of the mediating role of engagement in this study contributes to our knowledge of engagement and extends the application of engagement mediation models to a context-specific setting, that is, higher education.

\section{1 | Implications and recommendations for administrative leaders in higher education}

Findings from this study indicated that psychological climate, engagement, and psychological well-being are positively associated with each other, and that engagement mediated the relationship between psychological climate and psychological well-being. To maintain and/or improve organizational performance, college and university administrators must focus on the use of evidence-based strategies that empower faculty and staff, as this is key to developing a workplace climate that fosters engagement (Gilbert, Laschinger, \& Leiter, 2010). Thus, specific to higher education, administrators-from presidents to unit level supervisors-must actively work to ensure that their employees feel valued and useful, as it promotes engagement and in turn positively impacts psychological well-being. We believe this recommendation to be prudent considering increasing importance that colleges and universities are placing on wellness programs in a bid to improve well-being (Cooper \& Barton, 2016; Fullerton, 2011). These programs combine a variety of tools such as extensive awareness building through health education, risk assessments, and lifestyle coaching all aimed at encouraging positive lifestyle changes to enhance the quality of life of its employees (Birdee et al., 2013). While the proliferation of wellness programs in higher education is laudable, it cannot, and should not, be used in isolation to improve well-being. Rather, institutions of higher education should view these programs as a supplement to a sustained positive work environment. This is because the way faculty and staff interpret their work environments impacts their engagement, and subsequently impacts their psychological well-being. To create an engaging work environment for their employees, university and college administrators should consider the following three practical suggestions- promoting leadership development, conducting periodic climate audits, and encouraging acts of kindness.

\section{2 | Leadership development}

Leaders play in important role in the culture of an organization, and changing or influencing organizational culture to recognize and include engagement requires support from leadership. Higher education administrators should identify 
leader behaviors that foster engagement in the workplace and use this information to organize engagement-focused leadership training and onboarding for current and future leadership hires. This leadership training could be focused on explaining what engagement means within the institution, why it is important to faculty and staff, and the benefits leaders can get from focusing on engagement (e.g., increased performance, reduced turnover). A unique focus of this training could be identifying roles that leaders should play to help subordinates improve and sustain their engagement. Specifically, leaders should be trained on enhancing subordinates' personal resources such as positive thinking, goal setting, time management and stress management (see Schaufeli \& Salanova, 2010). Leader focused behaviors and self-leadership are beneficial to organizations because they are associated with higher levels of engagement (Breevaart, Bakker, Demerouti, \& Derks, 2016). Thus, by using leadership training to develop and enhance employee personal resources, colleges and universities can use leaders to stimulate engagement in the workplace.

\section{3 | Climate audits}

College and University administrators may consider investing in conducting periodic climate audits to assess faculty and staff engagement levels. The purpose of these audits would be to reveal information that could aid the development of further measures to improve engagement. These audits could include an assessment of the work climate for job stressors such as work overload and role problems, as well as unwanted outcomes such as absenteeism and counterproductive work behaviors. Information from these periodic audits can then be used to inform the development of training, or even modify existing strategic engagement goals. HRD scholars and practitioners have for many years championed the use of audits to monitor the effectiveness of interventions (Clardy, 2005). The strength of the use of audits in HRD practice lies in the richness of the data obtained from the interventions. As such, an effective climate audit should yield information such as in-depth descriptions of engagement interventions in place, sample employee interviews about workplace climate, and training records. This level of detail is imperative when conducting audits because it allows organizational leaders to make correct decisions about specific HRD interventions.

\section{4 | Acts of kindness}

The act of practicing kindness is based on the theory of caring, which is described as a genuine and ongoing interest in others that goes beyond feeling and concern, and can be demonstrated by acts of compassion (Kroth \& Keeler, 2009). While caring has traditionally been associated with helping professions such as counseling, business organizations are beginning using this concept as a mechanism to gain a competitive advantage by attracting and retaining talent (Kroth \& Keeler, 2009). Grounded in the caring theory, a specific idea that can be adopted by leaders of units and small teams in higher educational institutions (e.g., Department Chairs, maintenance supervisors etc.) is a kindness drive. The kindness drive would require all employees to be intentional about practicing kind acts over a period of time (e.g., 21 days) with the view to assimilating it into the culture of the team. Examples of kind acts that should be encouraged include simple actions such holding doors or elevators open for others, exchanging pleasantries, leaving hand written notes of appreciation, and brewing another pot of coffee after taking the last cup. Another intervention that can be implemented is story telling. There is a lot of research that has shown that sharing good news about positive experiences and accomplishments elicits positive emotions (Gable, Reis, Impett, \& Asher, 2004). As pointed out by Shuck et al. (2017), positive emotion is a core component of engagement and the more positive emotions a person experiences at work, the more likely they are to be engaged. To improve and sustain engagement, leaders of units, teams, and departments should consider weaving good news into compelling stories that can be celebrated by all employees. This could include tenure and promotion, newly published research, work milestones, and retirements. Concerted efforts to repeatedly use story telling to share good news result in a compounding of positive events that are more likely to be remembered and associated with the workplace (Schaufeli \& Salanova, 2010). 


\section{LIMITATIONS AND RECOMMENDATIONS FOR FUTURE RESEARCH}

As with any quantitative study, the generalization of findings from this study is dependent on the quality of data and appropriateness of the statistical methods used. There are a couple of limitations to note. First, we must address the issue of sample size. A known limitation of using online surveys for research is the low response rates (Dillman et al., 2009). This affected our final sample size, and as a result limited our ability to use more robust statistical measures such as structural equation modeling (SEM) that require large sample sizes (Nevitt \& Hancock, 2001). A larger sample size would have allowed us to test our proposed mediation analyses in one model as opposed to two. A related issue connected to the limitation of sample size we noted in our study was the presence of ceiling effects. The means of each of the variables we examined were high, indicating that most of the participants experienced positive climate, high engagement, and positive well-being. Consequently, the correlations we found might be weaker than what actually exist in higher education, and the mediating effects might not be observed when they are in fact present. A larger sample size might have provided more variation in the scores of each of the variables and countered the ceiling effects noted in this study.

We also noted earlier that the use of the MOS-10 scale could have impacted the significance of the mediation results where physical well-being was tested. The MOS-10, as with many latent variable scales, is subjective and therefore we recommend that future researchers consider using more objective measures of physical well-being including the use of bio data (e.g., heart rate, blood pressure) to assess whether engagement mediates the relationship between psychological climate and physical well-being among employees in higher education. Using objective measures such as bio data is less likely to produce scores that are range restricted and provide a better assessment of the relationship between psychological climate, engagement, and well-being. For example, an experimental research approach could be taken where participants are randomly distributed in two groups to work on a task and complete an engagement survey afterward. One group could have a leader who has been identified as toxic (e.g., consistently raising their voice at teammates) and the other a supportive leader (e.g., encourages teammates). Biodata obtained from both groups before and after the task can be compared to examine whether engagement is associated with better levels of physical well-being. Alternatively, this experiment could be conducted longitudinally to investigate whether higher levels of engagement correspond with better physical well-being over time.

Finally, we recommend future research consider sampling higher education employee from other countries to allow for increased generalizability of results. In addition, researchers could explore how cultural variances such as power distance, individualism versus collectivism, and uncertainty avoidance (Hofstede, 1983) might impact employees' interpretation of their work environment, and subsequently impact their well-being. In collectivistic cultures for example, the sense of self is embedded into social groups, meaning that frequent social interaction could positively influence the psychological climate the workplaces as compared to more individualistic cultures (Schaufeli \& Salanova, 2010). The manifestation of climate, engagement, and well-being within different cultural contexts could yield new information that might inform HRD theory, research, and practice. Cross-cultural work coalescing around these areas would be particularly welcome by the HRD community, as there is growing interest in examining HRD at a national level to identify how factors such as sociocultural and political environment affect human capital development (Alagaraja \& Wang, 2012).

\section{ORCID}

Kobena Osam (1D https://orcid.org/0000-0003-2920-8692

Brad Shuck (D) https://orcid.org/0000-0001-8768-7690

\section{REFERENCES}

Alagaraja, M., \& Wang, J. (2012). Development of a national HRD strategy model: Cases of India and China. Human Resource Development Review, 11(4), 407-429. https://doi.org/10.1177/1534484312446190 
Altunel, M. C., Kocak, O. E., \& Cankir, B. (2015). The effect of job resources on work engagement: A study on academicians in Turkey. Educational Sciences: Theory and Practice, 15(2), 409-417.

Baron, R. M., \& Kenny, D. A. (1986). The moderator-mediator variable distinction in social psychological research: Conceptual, strategic, and statistical considerations. Journal of Personality and Social Psychology, 51(6), 1173-1182.

Birdee, G. S., Byrne, D. W., McGown, P. W., Rothman, R. L., Rolando, L. A., Holmes, M. C., \& Yarbrough, M. I. (2013). Relationship between physical inactivity and health characteristics among participants in an employee wellness program. Journal of Occupational and Environmental Medicine/American College of Occupational and Environmental Medicine, 55(5), 514-519. https://doi.org/10.1097/jom.0b013e31827f37d7

Breevaart, K., Bakker, A. B., Demerouti, E., \& Derks, D. (2016). Who takes the lead? A multi-source diary study on leadership, work engagement, and job performance. Journal of Organizational Behavior, 37(3), 309-325. https://doi.org/10.1002/ job.2041

Brown, S. P., \& Leigh, T. W. (1996). A new look at psychological climate and its relationship to job involvement, effort, and performance. Journal of Applied Psychology, 81(4), 358-368. https://doi.org/10.1037//0021-9010.81.4.358

Christian, M. S., Garza, A. S., \& Slaughter, J. E. (2011). Work engagement: A quantitative review and test of its relations with task and contextual performance. Personnel Psychology, 64, 89-136. https://doi.org/10.1111/j.1744-6570.2010. 01203.x

Clardy, A. (2005). Reputation, goodwill, and loss: Entering the employee training audit equation. Human Resource Development Review, 4(3), 279-304.

Cohen, J. (1988). Statistical power analysis for the behavioral sciences (2nd ed.). Hillsdale, NJ: Erlbaum.

Cooper, K., \& Barton, G. C. (2016). An exploration of physical activity and wellbeing in university employees. Perspectives in Public Health, 136(3), 152-160. https://doi.org/10.1177/1757913915593103

Demerouti, E., Mostert, K., \& Bakker, A. B. (2010). Burnout and work engagement: A thorough investigation of the independency of both constructs. Journal of Occupational Health Psychology, 15(3), 209.

Dillman, D. A., Phelps, G., Tortora, R., Swift, K., Kohrell, J., Berck, J., \& Messer, B. L. (2009). Response rate and measurement differences in mixed-mode surveys using mail, telephone, interactive voice response (IVR) and the internet. Social Science Research, 38(1), 1-18.

Eisele, P., \& D'Amato, A. (2011). Psychological climate and its relation to work performance and well-being: The mediating role of organizational citizenship behavior (OCB). Baltic Journal of Psychology, 12(1-2), 4-21.

Fairlie, P. (2017). Work engagement and employee well-being. In B. Ronald \& P. Kathleen (Eds.), Research handbook on work and well-being (pp. 292-313). Cheltenham, England: Edward Elgar.

Fredrickson, B. L. (1998). What good are positive emotions? Review of General Psychology, 2, 300-319. https://doi.org/10. 1037/1089-2680.2.3.300

Fredrickson, B. L. (2001). The role of positive emotions in positive psychology: The broaden-and-build theory of positive emotions. American Psychologist, 56, 218-226. https://doi.org/10.1037/0003-066X.56.3.218

Fredrickson, B. L., \& Branigan, C. (2005). Positive emotions broaden the scope of attention and thought-action repertoires. Cognition and Emotion, 19, 313-332.

Fullerton, D. S. (2011). A collaborative approach to college and university student health and wellness. New Directions for Higher Education, 2011(153), 61-69. https://doi.org/10.1002/he.427

Gable, S. L., Reis, H. T., Impett, E. A., \& Asher, E. R. (2004). What do you do when things go right? The intrapersonal and interpersonal benefits of sharing positive events. Journal of Personality and Social Psychology, 87(2), 228-245. https:// doi.org/10.1037/0022-3514.87.2.228

García-Sierra, R., Fernández-Castro, J., \& Martínez-Zaragoza, F. (2016). Work engagement in nursing: An integrative review of the literature. Journal of Nursing Management, 24(2), E101-E111.

Gilbert, S., Laschinger, H. K., \& Leiter, M. (2010). The mediating effect of burnout on the relationship between structural empowerment and organizational citizenship behaviours. Journal of Nursing Management, 18(3), 339-348.

Giroux, H. A. (2009). Democracy's nemesis: The rise of the corporate university. Cultural Studies? Critical Methodologies, 9(5), 669-695. https://doi.org/10.1177/1532708609341169

Goetzel, R. Z., Henke, R. M., Tabrizi, M., Pelletier, K. R., Loeppke, R., Ballard, D. W., \& Serxner, S. (2014). Do workplace health promotion (wellness) programs work?. Journal of Occupational and Environmental Medicine, 56(9), 927-934.

Grant, A. M., Campbell, E. M., Chen, G., Cottone, K., Lapedis, D., \& Lee, K. (2007). Impact and the art of motivation maintenance: The effects of contact with beneficiaries on persistence behavior. Organizational Behavior \& Human Decision Processes, 103(1), 53-67.

Harter, J. K., Schmidt, F. L., Asplund, J. W., Killham, E. A., \& Agrawal, S. (2010). Causal impact of employee work perceptions on the bottom line of organizations. Perspectives on Psychological Science, 5(4), 378-389.

Hayes, A. F., \& Rockwood, N. J. (2017). Regression-based statistical mediation and moderation analysis in clinical research: Observations, recommendations, and implementation. Behaviour Research and Therapy, 98, 39-57. https://doi.org/10. 1016/j.brat.2016.11.001 
Hemphill, J. F. (2003). Interpreting the magnitudes of correlation coefficients. American Psychologist, 58(1), 78-80. https:// doi.org/10.1037/0003-066X.58.1.78

Henson, R. K. (2001). Understanding internal consistency reliability estimates: A conceptual primer on coefficient alpha. (methods, plainly speaking). Measurement and Evaluation in Counseling and Development, 34(3), 177-190.

Halbesleben, J. R. (2010). A meta-analysis of work engagement: Relationships with burnout, demands, resources, and consequences. Work engagement: A handbook of essential theory and research. (Vol. 8, pp. 102-117). New York, NY: Psychology Press.

Hofstede, G. (1983). The cultural relativity of organizational practices and theories. Journal of International Business Studies, 14(2), 75-89. https://doi.org/10.1057/palgrave.jibs.8490867

Iverson, R. D., Olekalns, M., \& Erwin, P. J. (1998). Affectivity, organizational stressors, and absenteeism: A causal model of burnout and its consequences. Journal of Vocational Behavior, 52, 1-23. https://doi.org/10.1006/jvbe.1996.1556

James, J. B., McKechnie, S., \& Swanberg, J. (2011). Predicting employee engagement in an age-diverse retail workforce. Journal of Organizational Behavior, 32(2), 173-196.

Kataria, A., Garg, P., \& Rastogi, R. (2013). Psychological climate and organizational effectiveness: Role of work engagement. IUP Journal of Organizational Behavior, 12(3), 33. https://doi.org/10.20474/jabs-2.4.3

Kataria, A., Rastogi, R., \& Garg, P. (2013). Organizational effectiveness as a function of employee engagement. South Asian Journal of Management, 20(4), 56-260. https://doi.org/10.1177/2319510x13519322

Keyko, K., Cummings, G. G., Yonge, O., \& Wong, C. A. (2016). Work engagement in professional nursing practice: A systematic review. International Journal of Nursing Studies, 61, 142-164.

Kim, W., Kolb, J. A., \& Kim, T. (2013). The relationship between work engagement and performance: A review of empirical literature and a proposed research agenda. Human Resource Development Review, 12(3), 248-276.

Kinman, G. (2014). Doing more with less? Work and wellbeing in academics. Somatechnics, 4(2), 219-235. https://doi.org/ 10.3366/soma.2014.0129

Kroth, M., \& Keeler, C. (2009). Caring as a managerial strategy. Human Resource Development Review, 8(4), 506-531. https:// doi.org/10.1177/1534484309341558

Maslach, C., Schaufeli, W. B., \& Leiter, M. P. (2001). Job burnout. Annual Review of Psychology, 52, 397-422. https://doi.org/ 10.1146/annurev.psych.52.1.397

Nazir, O., \& Islam, J. U. (2017). Enhancing organizational commitment and employee performance through employee engagement: An empirical check. South Asian Journal of Business Studies, 6(1), 98-114.

Nevitt, J., \& Hancock, G. R. (2001). Performance of bootstrapping approaches to model test statistics and parameter standard error estimation in structural equation modeling. Structural Equation Modeling, 8(3), 353-377.

Osam, E. K., Bergman, M., \& Cumberland, D. M. (2017). An integrative literature review on the barriers impacting adult learners' return to college. Adult Learning, 28(2), 54-60. https://doi.org/10.1177/1045159516658013

Parker, L. (2011). University corporatisation: Driving redefinition. Critical Perspectives on Accounting, 22(4), 434-450. https://doi.org/10.1016/j.cpa.2010.11.002

Pfaff, K., Baxter, P., Jack, S., \& Ploeg, J. (2014). An integrative review of the factors influencing new graduate nurse engagement in interprofessional collaboration. Journal of Advanced Nursing, 70(1), 4-20.

Reio, T. G., Jr. (2016). Nonexperimental research: Strengths, weaknesses and issues of precision. European Journal of Training and Development, 40(8/9), 676-690.

Rich, B. L., Lepine, J. A., \& Crawford, E. R. (2010). Job engagement: Antecedents and effects on job performance. Academy of Management Journal, 53(3), 617-635.

Ryff, C. D. (1995). Psychological well-being in adult life. Current Directions in Psychological Science, 4(4), 99-104. https://doi. org/10.1111/1467-8721.ep10772395

Ryff, C. D., \& Keyes, C. L. M. (1995). The structure of psychological well-being revisited. Journal of Personality and Social Psychology, 69(4), 719-727.

Schaufeli, W. (2012). Work engagement: What do we know and where do we go? Romanian Journal of Applied Psychology, 14(1), 3-10.

Schaufeli, W., \& Salanova, M. (2010). How to improve work engagement? In S. Albrecht (Ed.), The handbook of employee engagement: Perspectives, issues, research and practice (pp. 399-415). Northampton, MA: Edwin Elgar. https://doi.org/ 10.4337/9781849806374.00044

Schaufeli, W. B., \& Bakker, A. B. (2010). Defining and measuring work engagement: Bringing clarity to the concept. In A. B. Bakker \& M. P. Leiter (Eds.), Work engagement: A handbook of essential theory and research (pp. 10-24). New York, NY: Psychology Press.

Schaufeli, W. B., Taris, T. W., \& Van Rhenen, W. (2008). Workaholism, burnout, and work engagement: Three of a kind or three different kinds of employee well-being? Applied Psychology, 57, 173-203. https://doi.org/10.1111/j.1464-0597. 2007.00285.x

Shah, M. (2012). Renewing strategic planning in universities at a time of uncertainty. Perspectives: Policy and Practice in Higher Education, 17(1), 24-29. https://doi.org/10.1080/13603108.2012.679753 
Shin, J. C., \& Jung, J. (2014). Academics job satisfaction and job stress across countries in the changing academic environments. Higher Education, 67(5), 603-620.

Shuck, B., Adelson, J. L., \& Reio, T. G., Jr. (2017). The Employee Engagement Scale: Initial evidence for construct validity and implications for theory and practice. Human Resource Management, 56(6), 953-977. https://doi.org/10.1002/hrm.21811

Shuck, B., Alagaraja, M., Rose, K., Owens, J., Osam, K., \& Bergman, M. (2017). The health-related upside of employee engagement: Exploratory evidence and implications for theory and practice. Performance Improvement Quarterly, 30(3), 165-178. https://doi.org/10.1002/piq.21246

Shuck, B., Osam, K., Zigarmi, D., \& Nimon, K. (2017). Definitional and conceptual muddling: Identifying the positionality of employee engagement and defining the construct. Human Resource Development Review, 16(3), 263-293.

Shuck, B., \& Reio, T. G., Jr. (2014). Employee engagement and well-being: A moderation model and implications for practice. Journal of Leadership \& Organizational Studies, 21(1), 43-58. https://doi.org/10.1177/1548051813494240

Shuck, B., Reio, T. G., Jr., \& Rocco, T. S. (2011). Employee engagement: An examination of antecedent and outcome variables. Human Resource Development International, 14(4), 427-445. https://doi.org/10.1080/13678868.2011.601587

Shuck, B., \& Wollard, K. (2010). Employee engagement and HRD: A seminal review of the foundations. Human Resource Development Review, 9(1), 89-110.

Silman, F. (2014). Work-related basic need satisfaction as a predictor of work engagement among academic staff in Turkey. South African Journal of Education, 34(3), 1-5.

Stewart, A. L., Hays, R. D., \& Ware, J. E. (1988). The MOS short-form general health survey: Reliability and validity in a patient population. Medical Care, 26(7), 724-735. https://doi.org/10.1097/00005650-198807000-00007

Van den Berg, B. A. M., Bakker, A. B., \& Ten Cate, T. J. (2013). Key factors in work engagement and job motivation of teaching faculty at a university medical centre. Perspectives on Medical Education, 2(5-6), 264-275.

Watkins, J. M., \& Stavros, J. M. (2010). Appreciative inquiry: OD in the post-modern age. In W. J. Rothwell, J. M. Stavros, R. L. Sullivan, \& A. Sullivan (Eds.), Practicing organization development: A guide for leading change (3rd ed., pp. 158-181). San Francisco, CA: Pfeiffer.

Xanthopoulou, D., Bakker, A. B., Demerouti, E., \& Schaufeli, W. B. (2009). Work engagement and financial returns: A diary study on the role of job and personal resources. Journal of Occupational and Organizational Psychology, 82, $183-200$. https://doi.org/10.1348/096317908X285633

\section{AUTHOR BIOGRAPHIES}

Dr. Kobena Osam is an Assistant Professor in Organizational Leadership and an affiliate faculty member of the Masters in Public Administration Program at Northern Kentucky University. His primary research interest is focused on employee engagement, with a specific focus on exploring ways to create, manage and sustain a happier and healthier workforce. Dr. Osam's additional research interests include corporate social responsibility and performance improvement.

Dr. Brad Shuck is Associate Professor in the Department of Educational Leadership, Evaluation, and Organizational Development at the University of Louisville. He also serves as Principle Consultant of LEAD Research, LLC, an advanced human resource analytics consulting group focused on emerging technologies related to leadership, engagement, and design. His primary areas of research include the application, meaning, and measurement of employee engagement, emerging areas of positive psychology, and leader development.

Dr. Jason Immekus is an Associate Professor in the Department of Educational Leadership, Evaluation, and Organizational Development at the University of Louisville. His research areas are focused on the use of statistical models to address the psychometric properties of item and test-level data, including: factor structure, differential item functioning, and test score invariance.

How to cite this article: Osam K, Shuck B, Immekus J. Happiness and healthiness: A replication study. Human Resource Development Quarterly. 2020;31:75-89. https://doi.org/10.1002/hrdq.21373 